\title{
Ceftazidime with other Drugs Complexation Studied by UV Spectrophotometrically and Exploration of Antimicrobial Activity, In-Vitro Investigation
}

\author{
Shiba Das and Md Shahidul Islam* \\ Department of pharmacy, University of Science and Technology Chittagong (USTC), Chattogram, Bangladesh \\ *Corresponding author: Md Shahidul Islam, Department of pharmacy, University of Science and Technology Chittagong \\ (USTC), Chattogram, Bangladesh
}

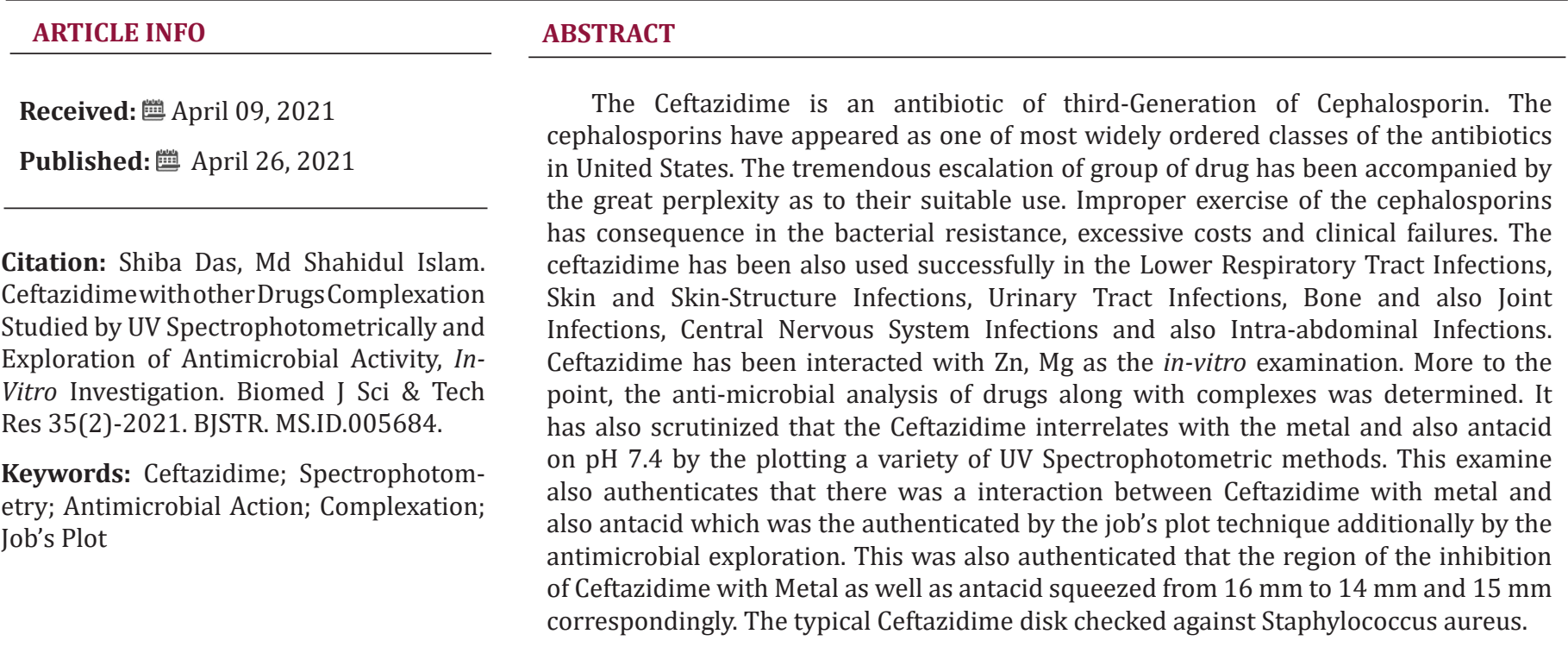

\section{Introduction}

Ceftazidime is the semisynthetic, beta-lactam, broadspectrum, antibacterial drug for the parenteral administration. This is a pentahydrate of pyridinium compound [1]. At this time drug interaction be competent of the simply be dissimilar as the interaction connecting a drug in addition to additional material with intention of the stop medicine commencing the phase as expected [2]. These correlations may happen by reason of be short of the knowledge regarding the principle ingredients associated in related substances [3]. Two medicines are antagonistic at what time their interaction occurs a reduce in special effects of one or else both of medicines. The dissimilar responses of receptor to act of a medicine has effected in number of arrangements, which use expressions such as "partial agonist", "competitive agonist" etc. This is even expected that a lot of authors would mismanage any given arrangement [4] Commonly iron complexes were used in convey of oxygen in human blood as well as tissues. An mature at rest takes $250 \mathrm{ml}$ of uncontaminated oxygen for each minute, these oxygen conceded by metal complex convey system recognized heame, alloying oxygen to go away the blood at what time it arrives the tissue [5]. Antibiotic and metal interaction and successfully found there after interaction result. Also, the antimicrobial activity of drug and the metals complexes were determined. This has been seen that the antibiotic interacts along with metal at the $\mathrm{pH} 7.4$. The different essential metal intricate of the many drugs has been synthesized in addition to characterized by the techniques like NMR, UV, atomic absorption, FT-IR as well as elemental analysis. Spectroscopic, IR Spectroscopic, disk diffusion method, Biological assay studies of complexes [6]. On the other hand in this interaction there uses metals complex which are interaction with drug into our 
body. And have been use there various type of bacteria for finding zone of inhibition. Some paper there uses methanol and ethanol for disk diffusion result clearly showing [7].

\section{Materials \& Methods}

(Tables $1 \&$ 2) Ceftazidime stock solutions 250 milliliter of the $1 \times 10^{-2}$ Molar was set by the softening 1.386 gm of Ceftazidime solution in 250 milliliters of Demineralized Water (DMW) in a 250 milliliters volumetric flask. The reserve solutions were thinned to the desired potency by buffer solutions [8].

Table 1: List of chemicals and reagents.

\begin{tabular}{|c|c|c|}
\hline Serial No & Name & Source \\
\hline 1 & Ceftazidime & $\begin{array}{c}\text { Gift samples from Incepta } \\
\text { pharmaceuticals Ltd. }\end{array}$ \\
\hline 2 & Zinc Sulphate (Metal) & Merck ltd, Mumbai, India \\
\hline 3 & $\begin{array}{c}\text { Magnesium Hydroxide } \\
\text { (Antacid) }\end{array}$ & Merck ltd, Mumbai, India \\
\hline 4 & $\begin{array}{c}\text { Sodium di-hydrogen } \\
\text { phosphate }\end{array}$ & $\begin{array}{c}\text { USTC, Foys lake, Chittagong, dept } \\
\text { of pharmacy }\end{array}$ \\
\hline 5 & $\begin{array}{c}\text { Disodium hydrogen } \\
\text { phosphate }\end{array}$ & $\begin{array}{c}\text { USTC, Foys lake, Chittagong, dept } \\
\text { of pharmacy }\end{array}$ \\
\hline 6 & Phosphate Buffer & $\begin{array}{c}\text { USTC, Foys lake, Chittagong, dept } \\
\text { of pharmacy }\end{array}$ \\
\hline
\end{tabular}

Table 2: List of instruments \& equipments.

\begin{tabular}{|c|c|c|}
\hline Name & Model & Source \\
\hline pH Meter & PH-211 & Hanna,Romania \\
\hline UV Spectrophotometer & T80 & PG instrument Ltd, England \\
\hline Electronic Balance & AL-204 & Mettlertoleddo, Switzerland \\
\hline Pipette & & Fischer scientific,Germany \\
\hline
\end{tabular}

\section{Preparation of Metal Solutions}

For the basis of 0.01 Molar Zn solution such as zinc sulfate hepta hydrate ( precisely $0.28754 \mathrm{gm}$ ) was assessed exactly in addition to the initiated with assist of funnel in the $100 \mathrm{ml}$ volumetric flasks, softened in the DM water in addition to the framework to mark by the alike solvent. These principal solutions were supplementary diluted ten folds in equivalent solvent in company with the concluding solution was $0.0001 \mathrm{M}$ concentration.

\section{Preparation of Antacid Solutions}

For the grounding of 0.01 Molar antacid solution like $\mathrm{Mg}(\mathrm{OH})_{2}$ $(0.0740 \mathrm{gm})$ was assessed accurately as well as initiated with facilitate of the funnel in the 100 milliliters volumetric flask, and softened in demineralized water also construct up to the mark by identical solvent. This primary solution was further diluted ten crinkles in the identical solvents and the final also solutions were $0.0001 \mathrm{M}$ concentrations.

\section{Grounding of the Buffer Solutions}

To get set buffer solution 1.76 grams of disodium hydrogen phosphate was softened in demineralized water by 2.43 grams of solution dihydrogen phosphate in addition to the $\mathrm{pH}$ was adjusted to $\mathrm{pH} 7.4$ as well as volume was also completed to 1000 milliliters with equivalent solution.

\section{Grounding of the Typical Curve of the Ceftazidime}

Ceftazidime reserve solutions at $\mathrm{pH} 7.4$ in addition to the concentrations of $1 \times 10^{-5}$ Molar was introduced in unlike concentration to 10 test tubes and to have later concentrations

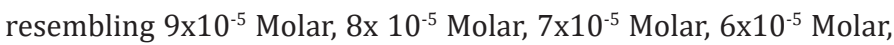
$5 \times 10^{-5}$ Molar, $4 \times 10^{-5}$ Molar, $3 \times 10^{-5}$ Molar, $2 \times 10^{-5}$ Molar, $1 \times 10^{-5}$ Molar. Now solutions were rightfully mixed. Then absorbance rates of solutions were found at the $500 \mathrm{~nm}$ throughout UV spectrometer [9].

\section{Using Disc Diffusion Process}

Solution of commemorated concentrations (Like $3 \mu \mathrm{g} / \mathrm{ml}$ ) of test samples were completed during dissolving measured quantity of trials in calculated quantity of solvents. The dried in addition to sterilized filter paper discs (such as $6 \mathrm{~mm}$ as a diameter) are afterward impregnated with recognized amounts of trial matters by using micropipette. Discs holding experiment substances were placed on the nutrient agar media consistently seeded by the test organism, idiosyncratic antibiotic discs in company with blank discs were exploited as a positive as well negative control. These plates were kept at the low temperature like $4{ }^{\circ} \mathrm{C}$ for 24 hours to allow maximum diffusion. Throughout this moment in times desiccated discs drain off the water from the adjacent medium and trial samples liquefy along with the extensive of trial disc. The diffusion occurs according to the physical rule so as to manages diffusion of molecules during the agar gel. Therefore there was a steady alter of trial matters concentrations in the medium adjoining disc [10].

\section{Results and Discussion}

From the succeeding Tables $3 \& 4$, this can examine to absorbance of Ceftazidime enhances with enhancing the concentration in keeping with the Beer Lambert's equation. From Table 5, it can monitor that absorbance of Ceftazidime is different and it interacts with $\mathrm{Mg}(\mathrm{OH})_{2}$. From Table 6, it can monitor that interaction between the drug and also metal may guide to form complexes which have dissimilar light absorption ability and spectrum pattern is also altered. So any change and spectrum actions is regarded as the tool for primary contact from spectral studies. Outcome of the metals on Ceftazidime by Job's technique of incessant variation: Molar proportions of the complexes of metal salt were computed approximately through the Job;s method. The examined absorbance speeds were calculated in $\mathrm{pH} 7.4$ at varied concentration such as $1 \times 10^{-5}$ to $9 \times 10^{-5}$ Molar of Ceftazidime by metal. Then the Job's plots at $\mathrm{pH}$ were needed through plotting absorbance difference against mole part of drug (Table 7). From above we can monitor that Ceftazidime forms the strong 1:1 complexes with the zinc sulfate hepta hydrate which is designated as the inverted ' $\mathrm{V}$ ' shaped curve 
(Table 8). From above we can monitor that Ceftazidime forms the strong 1:1 complexes with the $\mathrm{Mg}(\mathrm{OH})_{2}$ which is designated as the inverted ' $v$ ' shaped curve (Table 9).

Table 3: Standard curve of Ceftazidime.

\begin{tabular}{|c|c|}
\hline Mx10 $^{-5}$ & Absorbance \\
\hline 1 & 0.674 \\
\hline 2 & 0.682 \\
\hline 3 & 0.696 \\
\hline 4 & 0.705 \\
\hline 5 & 0.718 \\
\hline 6 & 0.725 \\
\hline 7 & 0.732 \\
\hline 8 & 0.741 \\
\hline 9 & 0.746 \\
\hline
\end{tabular}

Table 4: Absorbance of Ceftazidime at different wavelength.

\begin{tabular}{|c|c|}
\hline Wavelength & Absorbance \\
\hline 200 & 0.139 \\
\hline 240 & 0.141 \\
\hline 280 & 0.441 \\
\hline 320 & 0.281 \\
\hline 360 & 0.208 \\
\hline 400 & 0.131 \\
\hline 440 & 0.136 \\
\hline 480 & 0.167 \\
\hline 520 & 0.19 \\
\hline 560 & 0.197 \\
\hline 600 & 0.227 \\
\hline 640 & 0.238 \\
\hline
\end{tabular}

Table 5: Spectral analysis of Ceftazidime with $\mathrm{Mg}(\mathrm{OH})_{2}$.

\begin{tabular}{|c|c|c|}
\hline Wavelength/nm & $\begin{array}{c}\text { Absorbance of } \\
\text { Ceftazidime }\end{array}$ & $\begin{array}{c}\text { Absorbance of } \\
\text { Ceftazidime with } \\
\text { Mg(0H)2 }\end{array}$ \\
\hline 200 & 0.139 & 0.645 \\
\hline 240 & 0.141 & 0.878 \\
\hline 280 & 0.441 & 0.764 \\
\hline 320 & 0.281 & 0.425 \\
\hline 360 & 0.208 & 0.284 \\
\hline 400 & 0.131 & 0.194 \\
\hline 440 & 0.136 & 0.237 \\
\hline 480 & 0.167 & 0.249 \\
\hline 520 & 0.19 & 0.271 \\
\hline 560 & 0.197 & 0.28 \\
\hline 600 & 0.227 & 0.291 \\
\hline 640 & 0.238 & 0.295 \\
\hline
\end{tabular}

Table 6: Combined Spectral analysis of Ceftazidime with $\mathrm{ZnSO}_{4}$. $7 \mathrm{H}_{2} \mathrm{O}$.

\begin{tabular}{|c|c|c|}
\hline Wavelength/nm & $\begin{array}{l}\text { Absorbance of } \\
\text { Ceftazidime }\end{array}$ & $\begin{array}{c}\text { Absorbance of } \\
\text { Ceftazidime with } \\
\mathrm{ZnSO}_{4} \cdot 7 \mathrm{H}_{2} \mathrm{O}\end{array}$ \\
\hline 200 & 0.139 & 0.444 \\
\hline 240 & 0.141 & 0.778 \\
\hline 280 & 0.441 & 0.663 \\
\hline 320 & 0.281 & 0.324 \\
\hline 360 & 0.208 & 0.183 \\
\hline 400 & 0.131 & 0.193 \\
\hline 440 & 0.136 & 0.206 \\
\hline 480 & 0.167 & 0.217 \\
\hline 520 & 0.19 & 0.232 \\
\hline 560 & 0.197 & 0.249 \\
\hline 600 & 0.227 & 0.261 \\
\hline 640 & 0.238 & 0.265 \\
\hline
\end{tabular}

Table 7: Values of job's plot of Ceftazidime with $\mathrm{ZnSO}_{4} \cdot 7 \mathrm{H}_{2} \mathrm{O}$.

\begin{tabular}{|c|c|c|c|c|c|}
\hline \multirow{2}{*}{$\begin{array}{l}\text { Concentration of } \\
\text { Ceftazidime Mx10-5 }\end{array}$} & $\begin{array}{c}\text { Absorbance of } \\
\text { Ceftazidime }\end{array}$ & $\begin{array}{c}\text { Concentration of } \\
\mathrm{ZnSO}_{4} \cdot 7 \mathrm{H}_{2} \mathrm{O}\end{array}$ & $\begin{array}{c}\text { Absorbance of } \\
\mathrm{ZnSO}_{4} \cdot 7 \mathrm{H}_{2} \mathrm{O}\end{array}$ & $\begin{array}{l}\text { Absorbance of } \\
\text { mixture }\end{array}$ & $\begin{array}{c}\text { Absorbance } \\
\text { difference }\end{array}$ \\
\hline & A & Mx10-5 & B & $\mathrm{C}$ & $D=(A+B)-C$ \\
\hline 1 & 0.674 & 9 & 0.289 & 0.212 & 0.751 \\
\hline 2 & 0.682 & 8 & 0.288 & 0.21 & 0.76 \\
\hline 3 & 0.696 & 7 & 0.289 & 0.21 & 0.775 \\
\hline 4 & 0.705 & 6 & 0.29 & 0.213 & 0.782 \\
\hline 5 & 0.718 & 5 & 0.291 & 0.212 & 0.797 \\
\hline 6 & 0.725 & 4 & 0.294 & 0.229 & 0.79 \\
\hline 7 & 0.732 & 3 & 0.283 & 0.226 & 0.789 \\
\hline 8 & 0.741 & 2 & 0.281 & 0.237 & 0.785 \\
\hline 9 & 0.746 & 1 & 0.279 & 0.251 & 0.774 \\
\hline
\end{tabular}


Table 8: Values of Job plot of Ceftazidime and $\mathrm{Mg}(\mathrm{OH})_{2}$.

\begin{tabular}{|c|c|c|c|c|c|}
\hline $\begin{array}{c}\text { Concentration of } \\
\text { Ceftazidime } \mathbf{M x 1 0 ^ { - 5 }}\end{array}$ & $\begin{array}{c}\text { Absorbance of } \\
\text { Ceftazidime } \\
\mathbf{A}\end{array}$ & $\begin{array}{c}\text { Concentration of } \\
\mathbf{M g}\left(\mathbf{O H} \mathbf{~}_{\mathbf{2}} \mathbf{M x 1 \mathbf { 1 0 } ^ { - 5 }}\right.\end{array}$ & $\begin{array}{c}\text { Absorbance of } \\
\mathbf{M g}(\mathbf{O H})_{2} \\
\mathbf{B}\end{array}$ & $\begin{array}{c}\text { Absorbance of } \\
\text { mixture } \\
\mathbf{C}\end{array}$ & $\begin{array}{c}\text { Absorbance } \\
\mathbf{d i f f e r e n c e} \\
\mathbf{D}=(\mathbf{A}+\mathbf{B})-\mathbf{C}\end{array}$ \\
\hline 1 & 0.674 & 9 & 0.192 & 0.216 & 0.65 \\
\hline 2 & 0.682 & 8 & 0.188 & 0.214 & 0.656 \\
\hline 3 & 0.696 & 7 & 0.195 & 0.22 & 0.671 \\
\hline 4 & 0.705 & 6 & 0.198 & 0.22 & 0.683 \\
\hline 5 & 0.718 & 5 & 0.205 & 0.222 & 0.701 \\
\hline 6 & 0.725 & 4 & 0.199 & 0.234 & 0.69 \\
\hline 7 & 0.732 & 3 & 0.194 & 0.238 & 0.688 \\
\hline 8 & 0.741 & 2 & 0.187 & 0.249 & 0.679 \\
\hline 9 & 0.746 & 1 & 0.185 & 0.264 & 0.667 \\
\hline
\end{tabular}

Table 9: Combined absorbance of drug with different metal and antacid.

\begin{tabular}{|c|c|c|}
\hline Ceftazidime & Ceftazidime with $\mathrm{ZnSO}_{4} \cdot 7 \mathrm{H}_{2} \mathrm{O}$ & Ceftazidime with $\operatorname{Mg}(\mathrm{OH}) 2$ \\
\hline 0.674 & 0.289 & 0.192 \\
\hline 0.682 & 0.288 & 0.188 \\
\hline 0.696 & 0.289 & 0.195 \\
\hline 0.705 & 0.29 & 0.198 \\
\hline 0.718 & 0.291 & 0.205 \\
\hline 0.725 & 0.294 & 0.199 \\
\hline 0.732 & 0.283 & 0.194 \\
\hline 0.741 & 0.281 & 0.187 \\
\hline 0.746 & 0.279 & 0.185 \\
\hline
\end{tabular}

Table 10: Diameter of the zone of inhibition.

\begin{tabular}{|c|c|c|}
\hline Bacteria Used & Standard Disk (Zone of Inhibition/mm) & Sample Disk (Zone of Inhibition) \\
\hline Staphylococcus aureus & \multirow{2}{*}{$16 \mathrm{~mm}$} & ${\text { Ceftazidime }+\mathrm{ZnSO}_{4} \cdot 7 \mathrm{H}_{2} \mathrm{O}}^{14 \mathrm{~mm}}$ \\
\hline Staphylococcus aureus & \multirow{2}{*}{$16 \mathrm{~mm}$} & Ceftazidime with $\mathrm{Mg}(\mathrm{OH})_{2}$ \\
\cline { 2 - 3 } & & $15 \mathrm{~mm}$ \\
\hline
\end{tabular}

\section{Antimicrobial Reading}

The antimicrobial efficiency of the trial representatives is calculated via their action to pass up the enlargement of the microorganisms neighboring recordings which provides the clear region of inhibition. Past incubation, the antimicrobial acts of the testing materials were finished through the measuring diameter of the zones of embarrassment inside millimeter throughout a very clear mm scale. The trial models were examined also in opposition to the Staphyloccopcus aureus. The typical Ceftazidime disk checked also in opposition to the Staphyloccopcus aureus. The outcomes of antimicrobial action, computed considering diameters of the zone of inhibition in mm were revealed in Table 10. Antimicrobial feeling testing of Ceftazidime against the Staphylococcus aureus later than interacting with the $\mathrm{ZnSO}_{4} \cdot 7 \mathrm{H}_{2} \mathrm{O}$ and also $\mathrm{Mg}(\mathrm{OH})_{2}$ solution correspondingly.
Now it has proved that the zone of the inhibition of Ceftazidime with Metal and also antacid $\mathrm{Zn}, \mathrm{Mg}$ diminished from the $16 \mathrm{~mm}$ to $14 \mathrm{~mm}$ and $15 \mathrm{~mm}$ correspondingly owing to the metal, used antacid and also drug interaction.

\section{Conclusion}

The classy spectrophotometric technique is very easy, straight in addition to worthwhile for fortitude of the drugs. Commencing this spectral interpretation, this has also been observed that Ceftazidime provides the pointed peak at $500 \mathrm{~nm}$. At what time the Zinc Sulfate additionally antacid solution like $\mathrm{Mg}(\mathrm{OH})_{2}$ merged with Ceftazidime 1:1 ratio and also the strong point of peak alters tremendously and absorption characteristics are also changed owing to the interaction even though the position of the complex do not alter. Then the antimicrobial analysis of an intermediary is very crucial to observe its spectrum in opposition to a variety 
of natures of pathogenic microorganisms. The Job's plot also have provided molar fraction of the complexes of Ceftazidime through the Zinc Sulfate as well as antacid solution such as $\mathrm{Mg}(\mathrm{OH})_{2}$. At pH 7.4 Ceftazidime structures sturdy 1:1 complexes throughout Zinc Sulfate plus antacid solution similar to $\mathrm{Mg}(\mathrm{OH})_{2}$ assigned as ' $\wedge$ ' shaped curves. These curves also can indicate the wellbuilt kinetics of complexation between Ceftazidime by the Zinc Sulfate in company with antacid solution similar to magnesium hydroxide. The trial models were checked also in opposition to the Staphylococcus aureus. The typical Ceftazidime disk also ensured in opposition to the Staphylococcus aureus. It was also examined that the antimicrobial action of Ceftazidime reduces and it structures complexes throughout $\mathrm{ZnSO}_{4} \cdot 7 \mathrm{H}_{2} \mathrm{O}$ as well as antacid solution similar to magnesium hydroxide. Thus, by the antimicrobial assessment, it was established that the zone of inhibition of the Ceftazidime with Metal and also antacid $\mathrm{Zn}, \mathrm{Mg}$ diminished from the $16 \mathrm{~mm}$ to $14 \mathrm{~mm}$ and $15 \mathrm{~mm}$ respectively.

\section{References}

1. Gentry LO (1985) Antimicrobial activity,pharmacokinetics,thera-peutic indications and adverse reactions of ceftazidime. Pharmacotherapy 5(5): 254-267.

2. Derbyshire PJ, Williamson PJ, Pedlar SJ, Speller DCE, Mott MG, et al. (1987) Ceftazidime in the treatment of febrile immunosuppressed children. J Antimicrob Chemother 12: 357-360.

\section{ISSN: 2574-1241}

DOI: $10.26717 /$ BJSTR.2021.35.005684

Md Shahidul Islam. Biomed J Sci \& Tech Res

(C) (P) This work is licensed under Creative Commons Attribution 4.0 License

Submission Link: https://biomedres.us/submit-manuscript.php
3. Fainstein V, Bodey GP, Elting L, Bolivar R, Keating MJ, et al. (1983) A randomized study of ceftazidime compared to ceftazidime and tobramycin for The treatment of infections in cancer patients. J Antimicrob Chemother 12: 101-110.

4. Fong IW, Tomkins KB (1985) Review of Pseudomonas aenrginosa meningitis with special emphasis on treatment with ceftazidime. Rev Infect Dis 7(5): 604-612.

5. Norrby SR (1985) Role of cephalosporins in the treatment of bac- terial meningitis in adults: overview with special emphasis on ceftazidime. Am J Med 79: 56-61.

6. Lopez KJV, Bertoluci DF, Vicente KM, Aquilla AMD, Santos SRC J (2007) Simultaneous determination of cefepime, vancomycin and imipenem in human plasma of burn patients by high-performance liquid chromatography. J Chromatogr 860(2): 241-245.

7. Denooz R, Charlier C (2008) Simultaneous determination of five $\beta$ - lactam antibiotics (cefepim, ceftazidim, cefuroxim, meropenem and piperacillin) in human plasma by high - performance liquid chromatography with ultraviolet detection. Ibid 864(1-2): 161-167.

8. Koppisett VS, Chandra N (2011) Influence of Alcohol and Smoking on Drug Action: A Step for better utilization of drugs. Journal of Chemical and Pharmaceutical Research 3(1): 242-248.

9. Sadowski CD (2012) Drug Interactions with Antacids Mechanisms and Clinical Significance. springer international journal 11(6): 395-407.

10. Billov S, Kizek R, Jelen F, Novotn P (2003) Square-wavevoltammetric determination of cefoperazone in abacterial culture, pharmaceutical drug, milk, and urine. Analytical and Bioanalytical Chemistry 377(2): 362-369.

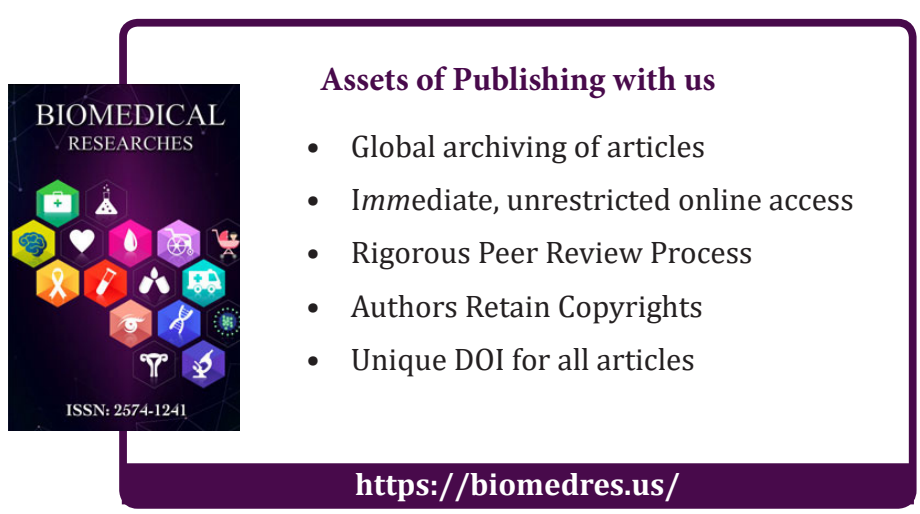

